\title{
Effect of Socio-Economic Status on Learning Ability of Bengali (Indian) Primary School Children
}

\author{
Sourav Manna, Amitava Pal, Prakash Chandra Dhara* \\ Ergonomics and Sports Physiology Division, Department Of Human Physiology with Community Health, Vidyasagar University, Midnapore, \\ W.B., India
}

\author{
Email address: \\ prakashdhara@rediffmail.com (P. C. Dhara)
}

\section{To cite this article:}

Sourav Manna, Amitava Pal, Prakash Chandra Dhara. Effect of Socio-Economic Statuson Learning Ability of Bengali (Indian) Primary

School Children. Advances in Applied Physiology. Vol. 1, No. 1, 2016, pp. 12-17. doi: 10.11648/j.aap.20160101.13

\begin{abstract}
Socioeconomic status is strongly associated with the cognitive ability and achievement during childhood. The purpose of the present study was to investigate the influence of age and socioeconomic status (SES) on learning ability among 5-10 years school going boys. A cross-sectional study was conducted on 322 school going boys from different districts of West Bengal state, India. The socio-economic status of the participants was evaluated by modified Kuppuswami scale. Learning ability of the participants was evaluated by Ray's auditory verbal learning test (RAVLT). The subjects were divided into lower, middle, upper SES groups. The results revealed that the 5 years old boys recalled significantly lesser words on each of the learning trials and showed significantly lower learning score compared to that of older boys. Age was significantly $(\mathrm{P}<0.001)$ and positively correlated with RAVLT performances. The participants belonged to the lower socioeconomic group recalled significantly lesser words on each of the learning trials and possessed significantly smaller learning score compared to that of middle and upper socioeconomic groups. Correlation analysis demonstrated that socioeconomic status had significant and positive correlation with RAVLT performances. On the contrary, age and socioeconomic status had significant negative correlation with forgetful speed. Multiple regression analysis demonstrated that even after controlling for the effect of the age, socioeconomic status had strong significant impact on learning of trials (LOT) and recognition (REC).
\end{abstract}

Keywords: Socioeconomic Status, Cross Sectional Study, Learning Abilities, Recognition

\section{Introduction}

Socioeconomic status (SES) of a person depends on the level of income and other social factors. However, economic status is a major factor related to the SES. Socioeconomic status refers to an individual's position within a social structure. It is one of the important determinant factors for the health status. Socioeconomic status is the combination of the social and economic variables. Several methods have been used for classifying different population by socioeconomic status such as Rahudkar scale 1960 [1], Udai Parikh scale 1964 [2], Jalota scale 1970 [3], Kulashrestha scale 1972 [4], Kuppuswami scale 1976 [5], Srivastava scale 1978 [6], Bharadwaj scale 2001 [7]. Kupuswami scale proposed in 1976 that measures socioeconomic status based on three variables such as education, occupation and household income [5]. Socioeconomic status influence the quality of physical and psychological environment throughout development [8]. The psychological research established that poverty is powerful risk factor for poor developmental outcomes [8] and poor cognitive and school performances [9].

Socio-economic status is strongly associated with the cognitive ability and achievement of the children. Poverty has a significant effect on neuro-cognitive development, thereby limiting of the educational opportunities that compromise the social relationship required for socioeconomic development $[10,11]$. The children who are living in a low income household or low socio-economic family, associated with deprivation of nutrient, maternal malnutrition of early sensory stimulation as well as exposure of environmental toxin [12-14]. Living in poverty is also associated with poorer overall physical health, and having greater chance for mental disorders, affecting attention and anxiety and mood. Socio-economic status is the combination of education, income and occupation. The family of low socioeconomic status have great difficulties to access a wide range of resource to promote and support of young children health and education as well as resources for social, emotional and cognitive development [15]. The studies also related that 
memory system induces medial temporal structures including hippocampus that's are important for memory consolidation and retrieval [16]. In several studies it was indicated that the memory and the performance were strongly and directly correlated with socio-economic status [17].

The memory is defined as the group of abilities that involves in acquisition, storage and retrieval of different type of information. The long term memory that allows the storage of information for a long periods of time where as short term memory that allows the storage of small quantities for a short period of time [18]. The working memories is defined as the memory system that involves storage and manipulation of information for performing wide variety of activities such as reasoning comprehensive and repetitive task [19].It has three subdivision - articulatory loop, visuospatial sketch pad, and central executive. The articulatory loop is responsible for processing and temporarily retaining the speech and knowledge. Several factors may affect the working memory, including educational level, sex and age [20].Several test has been applied to evaluate the learning and memory. One of the most important test frequently referred to international literature is the "Ray's auditory verbal learning test' [21], that is employed to evaluate the memory and learning. The Rays auditory verbal learning test measures the recent memory, verbal learning susceptibility to interference (proactive and retroactive), retention of information after a certain periods of time during which other activities are performed and recognition memory.

The purpose of the study was to investigate the influence on age and socio-economic status on learning on the basis of the performance on Ray's auditory verbal learning test (RAVLT) in male children having age range of 5-10 yrs.

\section{Methods and Materials}

\subsection{Sites and Subjects}

The socio-economic status (SES) of the participants was evaluated by modified Kuppuswami scale [22] considering the educational level, occupation and economic condition of the family and was expressed in terms of socioeconomic Scale. The socioeconomic status was determined by the scores suggested in this scale. The score obtained by each participant in education, occupation and income were added to get the final score and accordingly the participants were categorized. The subjects were categorized into three socioeconomic groups on the basis of SES scores, as shown below:

SES score 1-15: lower socioeconomic group

SES score 16-25: middle socioeconomic group

SES c score 26-29: upper socioeconomic group

\subsection{Ray's Auditory Verbal learning Test (RAVLT)}

The RAVLT [23] is a neuropsychological test of verbal learning and episodic declarative memory. The RAVLT was used to produce scores that measured short-term auditoryverbal memory, rate of learning, learning strategies, retroactive, and proactive interference, presence of confabulation of confusion in memory processes, retention of information, and differences between learning and retrieval.

In this experiment a list of 15 words (list A) was read loudly to the subject for consecutive 5 times. Each of the attempts was consisted of test of spontaneous retrieval. After the completion of fifth attempt, a list of interference, also consisted of 15 words (list B), was read to the subject and after reading of the words the students were asked for its retrieval (attempt B1). After attempt B1, the examiner instructed the individual student to recall the words which was belonged to list $\mathrm{A}$, without reading the list again the individual student was instructed to recall it again (attempt A6). For the evaluation of learning curve of the words during attempts A1 to A5, the learning rate during the attempts learning of trials (LOT) was calculated by the following formula: Sum of A1 to A5 - (5 x A1).

After an interval of 20-minutes, the examiner again asked the individual to remember the words that were belonged to list A, without reading the list (attempt A7). After the attempt A7, the individual was asked to attend for the test of memory recognition, in which a list that consists of 15 words from list A, 15 words from list B along with 20 distracting words (similar to the words in list A and B in phonological or semantic terms) were read to the individual. Then each of the word read aloud, the individual was asked to indicate if the word belongs to list A, or not. The total time for application of the RAVLT ranged from 35 to 40 minutes. The total sum of attempts, from 01 to 05 , and the rates of proactive interference were calculated by (B1/A1); retroactive interference was calculated by (A6/A5) and forgetting speed was calculated by (A7/A6). The result of the memory recognition test was calculated by adding the correct answers (when the individual correctly identified that the word belonged /did not belong to list A) - 35(total of distracting words). This same procedure, used in recognition memory tests, allowed to evaluate not only identification of targets (words in list A), but also took into account the effect of false positives (identification of distracting words) and false negatives (unidentified words in list A).

\subsection{Statistical Analysis}

Descriptive statistics, including means and standard deviations, were calculated for all the variables. To test the significant difference of the variables, the $t$ - test was performed. Pearson's correlation coefficient (r) was computed to test the association of all the variables. One-way analyses (Scheffe's procedure) were carried out to test for differences in Rey's auditory verbal learning test (RAVLT) performances across the different groups. To address the potential for confounding, regression analyses was undertaken. Age and socioeconomic status of the participants were entered into the model as independent variables. Socioeconomic status was included in the model as independent variables against RAVLT performances (LOT and REC) as dependent variables after adjusting the effect of age. P-value set at $<0.05$ level. Statistical analyses were performed using the statistical software IBM SPSS version 20. 


\section{Results}

The performance of Rey's auditory verbal learning test (RAVLT) of the primary school going boys has been presented in Table 1 according to the age of the subjects. From the results it was revealed that there were significant variations ( $p<0.05$ or less) of simple and composed scores of RAVLT among the children of different ages, excepting proactive interference (ITP) and forgetful speed (VE). There was general tendency of increasing the scores of most of the variables with advancement of age.

The results of post hoc analysis showed that the boys of lower age group (5 years) recalled significantly lesser $(p<0.001)$ words on each of the learning trial (A1to A7) and showed significantly lesser $(\mathrm{p}<0.001)$ learning score $(\mathrm{SUM})$ compared to that of 6 to 10 years old boys. On the other hand, the 10 years old boys recalled significantly more words $(\mathrm{p}<$ $0.001)$ than that of other age groups. Correlation analysis demonstrated that age was significantly $(\mathrm{P}<0.001)$ and positively correlated with all the simple and composite scores of RAVLT except proactive interference (ITP) and retroactive interference (ITR). On the contrary, age had significant $(\mathrm{P}<0.05)$ negative correlation with forgetful speed $(\mathrm{VE})$.

Table 1. Mean \pm SD of RAVLT performances cores by age groups.

\begin{tabular}{|c|c|c|c|c|c|c|c|c|c|c|c|c|c|}
\hline $\begin{array}{l}\text { AGE } \\
\text { (yrs) }\end{array}$ & A1 & A2 & A3 & A4 & A5 & A6 & A7 & ITP & ITR & VE & SUM & REC & LOT \\
\hline \multirow{2}{*}{$5(n=46)$} & $3.692 \pm$ & $3.891 \pm$ & $4.239 \pm$ & $5.108 \pm$ & $5.673 \pm$ & $3.108 \pm$ & $3.282 \pm$ & 0.771 & 0.567 & $1.097 \pm$ & 22.282 & $4.652 \pm$ & \multirow{2}{*}{$5.434 \pm 3.17$} \\
\hline & 1.08 & 1.48 & 1.18 & 1.25 & 1.41 & 0.82 & 0.75 & \pm 0.26 & \pm 0.16 & 0.27 & \pm 5.18 & 1.19 & \\
\hline \multirow{2}{*}{$6(n=54)$} & $5.03 \pm$ & $5.732 \pm$ & $6.714 \pm$ & $7.875 \pm$ & $8.535 \pm$ & $4.678 \pm$ & $4.928 \pm$ & 0.718 & $0.580 \pm$ & $1.087 \pm$ & 33.892 & $6.143 \pm$ & \multirow{2}{*}{$6.734 \pm 2.39$} \\
\hline & 1.92 & 2.19 & 2.34 & 2.75 & 3.29 & 1.60 & 1.55 & 0.23 & 0.20 & 0.22 & \pm 11.98 & 2.25 & \\
\hline \multirow{2}{*}{$7(n=58)$} & $4.810 \pm$ & $5.724 \pm$ & $6.568 \pm$ & $6.931 \pm$ & $7.775 \pm$ & $3.982 \pm$ & $3.931 \pm$ & 0.689 & 0.525 & $1.007 \pm$ & 31.810 & $6.689 \pm$ & \multirow{2}{*}{$6.224 \pm 3.39$} \\
\hline & 1.71 & 1.67 & 1.66 & 1.82 & 2.07 & 1.34 & 1.34 & 0.33 & \pm 0.16 & 0.22 & \pm 8.16 & 1.82 & \\
\hline \multirow{2}{*}{$8(n=62)$} & $5.080 \pm$ & $5.870 \pm$ & $6.661 \pm$ & $7.139 \pm$ & $7.741 \pm$ & $4.483 \pm$ & $4.654 \pm$ & 0.753 & $0.596 \pm$ & $1.056 \pm$ & 32.548 & $6.661 \pm$ & \multirow{2}{*}{$7.258 \pm 3.24$} \\
\hline & 1.25 & 1.34 & 1.29 & 1.57 & 1.61 & 1.41 & 1.20 & 0.29 & 0.17 & 0.19 & \pm 5.87 & 2.56 & \\
\hline \multirow{2}{*}{$9(\mathrm{n}=54)$} & $6.555 \pm$ & $7.518 \pm$ & $8.814 \pm$ & $9.743 \pm$ & 10.481 & $5.351 \pm$ & $5.370 \pm$ & 0.706 & $0.526 \pm$ & $1.008 \pm$ & 43.074 & $9.407 \pm$ & \multirow{2}{*}{$9.055 \pm 5.62$} \\
\hline & 1.66 & 1.91 & 1.85 & 2.22 & \pm 2.48 & 1.34 & 1.68 & 0.15 & 0.15 & 0.22 & \pm 8.71 & 2.42 & \\
\hline \multirow{2}{*}{$10(n=46)$} & $7.326 \pm$ & $8.656 \pm$ & $9.695 \pm$ & 10.782 & 11.869 & $6.021 \pm$ & $5.934 \pm$ & 0.773 & $0.513 \pm$ & $1.003 \pm$ & 48.239 & 10.891 & \multirow{2}{*}{$10.413 \pm 4.43$} \\
\hline & 2.51 & 2.75 & 2.58 & \pm 2.85 & \pm 3.03 & 1.59 & 1.55 & 0.23 & 0.08 & 0.19 & \pm 13.22 & \pm 3.61 & \\
\hline FRatio & $\begin{array}{l}30.912 \\
* * *\end{array}$ & $\begin{array}{l}34.043 \\
* * *\end{array}$ & $\begin{array}{l}50.308 \\
* * *\end{array}$ & $\begin{array}{l}43.450 \\
* * *\end{array}$ & $\begin{array}{l}40.011 \\
* * *\end{array}$ & $\begin{array}{l}27.719 \\
* * *\end{array}$ & $\begin{array}{l}23.200 \\
* * *\end{array}$ & 1.048 & $2.446^{*}$ & 1.992 & $\begin{array}{l}47.076 \\
* * *\end{array}$ & $\begin{array}{l}44.596 \\
* * *\end{array}$ & $11.757 * * *$ \\
\hline
\end{tabular}

${ }^{*} \mathrm{p}<0.05, * * \mathrm{p}<0.01, * * * \mathrm{p}<0.001$ [ITP-Proactive interference, ITR-Retroactive active interference VE-Forgetful speed, SUM-Addition of scoresfromA1-A5, REC-Recognition, LOT-Learning of trials].

In the present study the socioeconomic status (SES) of the study participants was assessed by modified Kuppuswami scale and the study participants were categorized into lower, middle and upper socioeconomic groups. From the results it was noted that about $30 \%$ of the participants were belonged to the lower socioeconomic group, $36 \%$ were belonged to the middle socioeconomic group and remaining $34.47 \%$ of the participants were belonged to the upper socioeconomic group. The scores of RAVLT of the primary school going boys were compared in variation to socioeconomic status (Table 2). The results of ANOVA showed a significant variation $(\mathrm{p}<0.001)$ in auditory verbal learning performances of the participants among different socioeconomic groups excepting proactive interference (ITP) and retroactive interference (ITR). From the results it was appeared that the performance scores were gradually increased from lower to higher SES, excepting ITP and VE. It was noted that there was a gradual decrease in the mean scores of VE $(p<0.01)$ and ITP (non-significantly). The post hoc analysis showed that the participants belonged to the lower socioeconomic group recalled significantly lesser words on each of the learning trials and significantly lower learning score compared to that of middle and upper socioeconomic groups (Table 2). The boys belonged to upper socioeconomic group recalled significantly more words than that of lower and middle socioeconomic groups.

Table 2. Mean \pm SD of RAVLT performance score by socioeconomic status (SES).

\begin{tabular}{|c|c|c|c|c|}
\hline RAVLT Performance & Lower SES $(n=96)$ & Middle SES (n=115) & Upper SES $(n=111)$ & F ratio \\
\hline A1 & $4.08 \pm 1.65$ & $5.17 \pm 1.69^{*}$ & $6.63 \pm 2.12 * \# \#$ & $50.35(\mathrm{p}<0.001)$ \\
\hline $\mathrm{A} 2$ & $4.75 \pm 1.7$ & $6.08 \pm 1.88 *$ & $7.58 \pm 2.53 * \# \#$ & $47.788(\mathrm{p}<0.001)$ \\
\hline A3 & $5.59 \pm 1.86$ & $6.97 \pm 1.93 *$ & $8.55 \pm 2.67 * \# \#$ & $47.038(\mathrm{p}<0.001)$ \\
\hline A4 & $6.17 \pm 1.91$ & $7.7 \pm 2.19 *$ & $9.61 \pm 2.94 * \# \#$ & $53.64(\mathrm{p}<0.001)$ \\
\hline A5 & $6.78 \pm 2.04$ & $8.54 \pm 2.48 *$ & $10.35 \pm 3.36^{* \# \#}$ & $44.879(\mathrm{p}<0.001)$ \\
\hline A6 & $3.5 \pm 1.26$ & $4.56 \pm 1.26^{*}$ & $5.59 \pm 1.53 * \# \#$ & $60.474(\mathrm{p}<0.001)$ \\
\hline A7 & $3.7 \pm 1.33$ & $4.7 \pm 1.38 *$ & $5.5 \pm 1.6 * \# \#$ & $39.753(\mathrm{p}<0.001)$ \\
\hline ITP & $0.76 \pm 0.32$ & $0.73 \pm 0.25$ & $0.71 \pm 0.17$ & $0.824(\mathrm{NS})$ \\
\hline ITR & $0.53 \pm 0.18$ & $0.55 \pm 0.15$ & $0.57 \pm 0.17$ & $1.049(\mathrm{NS})$ \\
\hline VE & $1.1 \pm 0.28$ & $1.05 \pm 0.21$ & $0.99 \pm 0.17 * \#$ & $5.46(\mathrm{p}<0.01)$ \\
\hline SUM & $27.38 \pm 8.43$ & $34.44 \pm 9.09 *$ & $42.72 \pm 12.99 * \# \#$ & $53.554(\mathrm{p}<0.001)$ \\
\hline REC & $5.33 \pm 1.75$ & $7.08 \pm 2.14^{*}$ & $9.39 \pm 3.59 * \# \#$ & $60.191(\mathrm{p}<0.001)$ \\
\hline LOT & $5.09 \pm 3.01$ & $7.45 \pm 3.64 *$ & $9.5 \pm 4.35 * \# \#$ & $35.343(\mathrm{p}<0.001)$ \\
\hline
\end{tabular}

w.r.t.Lower*p $<0.001$. w.r.t.Middle $\# \mathrm{p}<0.05 ; \# \# \mathrm{p}<0.001$. 
Correlation analysis demonstrated that socioeconomic status (SES) had significant and positive correlation with auditory verbal learning performances except proactive interference (ITP) (Table 3). On the contrary, socioeconomic status had significant $(\mathrm{P}<0.001)$ negative correlation with forgetful speed (VE). Such findings were noted among the boys of individual age groups as well as in composite groups of all ages. In composite group there was strong correlation $(\mathrm{p}<0.001)$ in all variables excepting ITR $(\mathrm{p}<0.05)$ and ITP (NS).

Table 3. Correlation coefficient between socioeconomic status and Rey's auditory verbal learning performance scores.

\begin{tabular}{|c|c|c|c|c|c|c|c|c|c|c|c|c|c|}
\hline Age & A1 & A2 & A3 & A4 & A5 & A6 & A7 & ITP & ITR & VE & SUM & REC & LOT \\
\hline 5 & $0.291 *$ & $0.302 *$ & $0.432 * *$ & $0.596 * * *$ & $0.602 * * *$ & $0.625 * * *$ & $0.323 *$ & 0.105 & 0.039 & $-0.414 * *$ & $0.554 * * *$ & $0.41 * *$ & $0.407 * *$ \\
\hline 6 & $0.69 * * *$ & $0.682 * * *$ & $0.703 * * *$ & $0.765 * * *$ & $0.687 * * *$ & $0.753 * * *$ & $0.708 * * *$ & -0.257 & 0.0023 & -0.252 & $0.738 * * *$ & $0.830 * * *$ & $0.48 * * *$ \\
\hline 7 & $0.616 * * *$ & $0.603 * * *$ & $0.613 * * *$ & $0.552 * * *$ & $0.498 * * *$ & $0.707 * * *$ & $0.655 * * *$ & -0.006 & $0.349 * *$ & -0.141 & $0.628 * * *$ & $0.551 * * *$ & $0.45 * * *$ \\
\hline 8 & $0.388 * *$ & $0.349 * *$ & $0.292 * *$ & $0.327 * *$ & $0.352 * *$ & $0.34 * *$ & 0.15 & 0.187 & 0.072 & -2.294 & $0.413 * * *$ & $0.47 * * *$ & $0.426 * * *$ \\
\hline 9 & $0.294 *$ & $0.445^{* *}$ & $0.385 * *$ & $0.339 * *$ & $0.392 * *$ & $0.598 * * *$ & $0.565 * * *$ & 0.172 & $0.258 *$ & 0.13 & $0.434 * * *$ & $0.691 * * *$ & $0.436 * * *$ \\
\hline 10 & $0.854 * * *$ & $0.843 * * *$ & $0.832 * * *$ & $0.899 * * *$ & $0.884 * * *$ & $0.814 * * *$ & $0.716 * * *$ & -0.491 & -0.112 & -0.183 & $0.896 * * *$ & $0.885 * * *$ & $0.826 * * *$ \\
\hline All & $0.501 * * *$ & $0.497 * * *$ & $0.471 * * *$ & $0.493 * * *$ & $0.48 * * *$ & $0.587 * * *$ & $0.513 * * *$ & -0.037 & $0.135 *$ & $-0.194 * * *$ & $0.515 * * *$ & $0.546 * * *$ & $0.465 * * *$ \\
\hline
\end{tabular}

$\mathrm{p}<0.05^{*} \mathrm{p}<0.01 * * \mathrm{p}<0.001 * * *$

Linear regression analysis of socioeconomic status with learning of trial (LOT) and Recognition (REC) was performed and it was revealed that socioeconomic status had significant association with LOT and REC (Table 4). Multiple regression analysis demonstrated that even after controlling for the effect of the age, socioeconomic status had strong significant impact on LOT and REC. Therefore, the socioeconomic status might be the best account for the variability of the auditory verbal learning performances.

Table 4. Regression analysis of socioeconomic status as independent variable and REC and LOT are dependent variables.

\begin{tabular}{|c|c|c|c|c|c|c|c|c|c|c|}
\hline \multirow{2}{*}{ Variables } & \multicolumn{6}{|c|}{ Unadjusted } & \multicolumn{4}{|c|}{ Adjusted\# } \\
\hline & B & SeB & $\beta$ & $\mathbf{R}^{2}$ change & Fchange & $\mathbf{T}$ & B & SeB & $\beta$ & $t$ \\
\hline REC & 0.202 & 0.017 & 0.546 & 0.298 & 135.757 & $11.65 * * *$ & 0.182 & 0.013 & 0.49 & $13.86^{* * *}$ \\
\hline LOT & 0.229 & 0.024 & 0.465 & 0.216 & 88.109 & $9.38 * * *$ & 0.213 & 0.023 & 0.432 & $9.32 * * *$ \\
\hline
\end{tabular}

$* * * \mathrm{p}<0.001 \#$ after adjusting age.

\section{Discussion}

The age and SES influenced the scores of all the sub-items. The study revealed that age and SES showed significant effect on learning and memory. The performance of simple scores A1 to A5, and composite scores (LOT, REC) revealed that recalling of words was gradually increased in both children of upper socio-economic and lower socioeconomic families. This improvement might be attributed to the learning which was mainly achieved due to the repeated reading of the word list.

The immediate recall performance (A1) was influenced by the age independently. The articulatory process and the articulatory loop were the key components of the working memory, whose function was to hold the auditory information in the form of memory. It was found that the increase of age (from 5 to 10 years) had a positive effect on the articulatory loop and articulatory process and there was a strong positive relationship between early recall (A1) and performance of school children $[24,25]$. The delayed recall (A7) was also influenced by age. Investigators proposed that the better performance of young children was due to the activity of the two main components, viz, articulatory loop and episodic buffer [26]. The key function of the episodic buffer was to integrate the information from the articulatory and visuo-spatial loop along long term memory material [27].

In the present study the socio-economic status showed an effect on learning process of the children. The level of SES affects emotion, and cognitive development in various degree [28-30]. Other studies [31, 33, 36-37, 39] also showed that the SES of childhood affect the cognitive development which had a positive co-relation with intelligence and academic achievement from the childhood to adolescence. Previous studies pointed out some factors that might have indirect effects on learning process of the children. A higher rate of depression, anxiety, and attention problem were observed among the children with lower SES back ground in comparison to that of higher SES back ground [29, 32-35, 38]. Several studies found that SES had extreme affect on various newer cognitive system such as language processing and moderate affect on the working memory and cognitive control [30, 40, 42]. Language problem and phonological awareness were also noted as an effect of SES [43]. It was postulated that SES was positively correlated with the functions of inferior frontal gyrus which was activated during language task [44]. The study also showed decreased language function of the left hemisphere in the children with low SES. The SES related difference in executive function of working memory has been noted in children and adult. The SES influenced verbal and spatial working memory in the children and adolescents and working memory in late childhood [30, 40, 41].

Efforts have been made by different investigators to explain the influence of socioeconomic status of the 
individual on the learning process in terms of neurological functions. The poverty affects the five consecutive cognitive functions such as language, executive function, memory, spatial cognition and visual function [45]. The left perisylvian region and other region of the temporal cortex involved in semantic, phonological and grammatical processing of language [46, 47].The medial temporal area including hippocampus was found to be significantly important for the consolidation of memory and retrieval [48]. Harman and Guad -agno showed in their studies that performance at memory task was strongly and directly corelated with SES [49]. The frontal cortex was highly susceptible to the negative effect of SES disparity [50]. Further, more studies revealed that parental SES was associated with delayed maturation of prefrontal cortex, impulsive decision making, delayed attention [51] and deficit of variety of cognitive ability, such as reading, learning, and language, that persisted into adulthood $[50,51]$. Brain having the capacity to rapid growth and changes that occurred into first 5 yrs of life, for that purpose necessary of adequate nutrient, and nurturance and care of a parents, and social climate for normal development were suggested [50, 52, 53]. In rich SES condition, the enriching activities such as learning and cognitive task that caused the growth of a new neurones in hippocampus, on the contrary, the stressful environment caused the opposite effect on hippocampus i.e. decrease the neurogenesis on that region [54-57].

\section{Conclusion}

The neuro-cognitive development was found to be directly related to socio-economic status. Low socioeconomic status was associated with decrease in the functioning of executive control, memory and language processing and decreased in the development of brain regions that were involved in socioemotional processing. Poverty affects the neural development. Correlation analysis demonstrated that socioeconomic status had significant and positive correlation with RAVLT performances. Lower socioeconomic status had significant negative correlation with forgetful speed. The severely low socioeconomic condition can be harmful for the children who are the future citizen of the country.

\section{References}

[1] Rahudkar WB. A scale for measuring socio-economic status of Indian farm families. Nay Agril Coll Mag, 1960; 34

[2] Parikh U, Trivedi G. Manual of socio-economic status scale (Rural), Manasayan, Delhi, 1964.

[3] Alota S, Pandey RN, Kapoor SD, Singh RN. Socioeconomic status questionnaire (urban), psycho- Centre, New Delhi, 1970.

[4] Kulshrestha SP, Day P. Socio-economic status scale (Urban) form-A, National Psychological Corporation, Agra, 1972.

[5] Kuppuswamy B. Manual of Socioeconomic Status (urban), Manasayan, Delhi, 1981.
[6] Srivastava GP. Socio-economic status scale (Urban), National Psychological Corporation, Agra, 1978.

[7] Bhardwaj RL. Manual for socio-economic status scale. National Psychological Corporation, Agra, 2001.

[8] Evans GW.The environment of childhood poverty. Am psychol. 2014; 59: 77-92.

[9] Brady-Smith C, Fauth, R, Brooks-Gunn J. Poverty and education: Children and adolescents. In Guthrie JW, editor, Encyclopedia of education. New York: Macmillan; 2002; 1910-1915.

[10] Hackman DA, Farah MJ, Meaney MJ. Socioeconomic status and the brain: Insights from human and animal research. Nat Rev. 2010; 11: 651-9.

[11] American Psychological Association. [Internet]. Washington, DC: The Association; [cited 2013 Apr 2]. Children, Youth, Families, and Socioeconomic Status [about 3 screens]. Available from: http://www.apa.org/pi/ses/resources/publications/factsheetcyf.aspx.

[12] de Kloet ER, Joëls M, Holsboer F. Stress and the brain: from adaptation to disease. Nat Rev Neurosci. 2005; 6(6): 463-75.

[13] American Psychological Association. [Internet]. Washington, DC: Association. [Updated 2013Jan; cited 2013 Apr 2]. Neurobehavioral effects of poverty. The SES Indicator [about 5 screens]. Available from: http://www.apa.org/pi/ses/resources/indicator/2013/01/poverty -behaviors.aspx.

[14] Cabeza R, Kingstone A, eds. Handbook of functional neuroimaging of cognition, 2nd ed. Cambridge, MA: MIT Press; 2006.

[15] Mueller CW, Parcel TL. Measures of socioeconomic status: Alternatives and recommendations. Child Development. 1981; 52(1): 13-30.

[16] Squire LR, Wixted JT. The cognitive neuroscience of human memory since H.M. Annu Rev Neurosci.2011; 34: 259-88.

[17] Herrmann D, Guadagno MA. Memory performance and Socio-Economic Status. Appl Cognit Psychol. 1997; 11(2): 113-120.

[18] Xavier GF. A Modularidade da memória e o sistema nervoso. Psicologia USP 1993; 4: 61-115.

[19] Baddeley A, Hitch G. Working memory. In: Bower GH (Ed). The psychology of learning and motivation. New York: Academic Press, 1974: 47-89

[20] Spreen O, Strauss, E. A Compendium of neuropsychological tests. 2nd Ed. New York: Oxford University Press, 1998: 326337.

[21] Rey A. L'éxamen clinique en psychologie. Paris: Press Universitaire de France, 1958.

[22] Kumar BP R, Shankar Reddy Dudala S R, AR Rao A R. Kuppuswamy's Socio-Economic Status Scale - a revision of economic parameter for 2012. International Journal of Research \& Development of Health. 2013; 1(1): 2-4.

[23] Bleecker ML, Bolla-Wilson K, Agnew J, Meyers DA. Agerelated sex differences in verbal memory. J Clin Psychol 1988; 44: 403-411. 
[24] Uchiyama CL, D'Elia LF, Dellinger AM, et al. Alternate forms of the Auditory-Verbal Learning Test: issues of test comparability, longitudinal reliability and moderating demographic variables. Arch Clin Neuropsychol 1995; 10: 133-145.

[25] Elst W, Boxtel MPJ, Breukelen GJP. Rey's verbal learning test: normative data for 1855 healthy participants aged 24-81 years and the influence of age, sex, education, and mode of presentation. J Intern Neuropsychol Soc 2005; 11: 290-302.

[26] Baddeley A. The episodic buffer: a new component of working memory? Trends Cogn Sci 2000; 4: 417-423.

[27] Query WT, Berger RA. ALVT memory scores as a function of age among general medical, neurologic and alcoholic patients. J Clin Psychol 1980; 36: 1009-1012.

[28] Adler NE, Rehkopf DF. US disparities in health: descriptions, causes and mechanisms. Annu. Rev. Public Health. 2008; 29: 235-252.

[29] Duncan GJ, Brooks-Gunn J, Klebanov PK. Economic deprivation and early childhood development. Child Dev. 1994; 65: 296-318.

[30] Noble KG, McCandliss BD, Farah MJ. Socioeconomic gradients predict individual differences in neurocognitive abilities. Dev. Sci. 2007; 10: 464-480.

[31] Sirin SR. Socioeconomic status and academic achievement: a meta-analytic review of research. Rev. Educ. Res. 2005; 75: 417-453.

[32] Merikangas KR, He JP, Brody D, Fisher PW, Bourdon K, Koretz DS Prevalence and treatment of mental disorders among US children in the 2001-2004 NHANES. Pediatrics. 2010; 125: 75-81.

[33] Goodman E, Slap GB, Huang B. The public health impact of socioeconomic status on adolescent depression and obesity. Am. J. Public Health. 2003; 93: 1844-1850.

[34] Shanahan L, Copeland W, Costello EJ, Angold A. Specificity of putative psychosocial risk factors for psychiatric disorders in children and adolescents. J. Child Psychol. Psychiatry. 2008; 49: 34-42.

[35] Tracy M, Zimmerman FJ, Galea S, McCauley E, Vander Stoep A. What explains the relation between family poverty and childhood depressive symptoms? J. Psychiatr. Res. 2008; 42: $1163-1175$

[36] Brooks-Gunn J, Duncan GJ. The effects of poverty on children. Future Child. 1997; 7: 55-71.

[37] McLoyd VC. Socioeconomic disadvantage and child development. Am. Psychol. 1998; 53: 185-204.

[38] Sirin SR. Socioeconomic status and academic achievement: a meta-analytic review of research. Rev. Educ. Res. 2005; 75: 417-453.

[39] Guo G, Mullan-Harris KM. The mechanisms mediating the effects of poverty on children's intellectual development. Demography. 2000; 37: 431-437.

[40] Farah MJ, et al. Childhood poverty: specific associations with neurocognitive development. Brain Res.2006; 1110: 166-174.
[41] Noble KG, Norman MF, Farah MJ. Neurocognitive correlates of socioeconomic status in kindergarten children. Dev. Sci. 2005; 8: 74-87.

[42] Kishiyama MM, Boyce WT, Jimenez AM, Perry LM, Knight RT. Socioeconomic disparities affect prefrontal function in children. J. Cogn. Neurosci. 2009; 21: 1106-1115.

[43] Whitehurst GJ. In: Research on Communication and Language Disorders: Contribution to Theories of Language Development. Adamson LB, Romski MA, editors. Baltimore, Maryland: Brookes Publishing; 1997; 233-266.

[44] Daniel A. Hackman, Martha J. Farah, and Michael J. Meaney, et al. Socioeconomic status predicts hemispheric specialization of the left inferior frontal gyrus in young children. Neuroimage. 2008; 40: 1392-1401.

[45] Noble KG, Norman MF, Farah MJ. The neurocognitive correlates of socioeconomic status in kindergarten children. Dev Sci. 2005; 8: 74-87.

[46] Catani M, Jones DK, Fftyche D. Perisylvian language networks of the human brain. Annals of Neurology. 2005; 57(1): 8-16.

[47] Binder JR, Frost JA, Hammeke TA, Cox RW, Rao SM, Prieto T. Human brain areas identified by functional magnetic resonance imaging. J Neurosci. 1997; 17(1): 353-362.

[48] Squire LR, Wixted JT. The cognitive neuroscience of human memory since H.M. Annu Rev Neurosci. 2011; 34: 259-88.

[49] Herrmann D, Guadagno MA. Memory performance and Socio-Economic Status. Appl Cognit Psychol. 1997; 11(2): 113-120.

[50] Kishiyama MM, Boyce WT, Jimenez AM, Perry LM, Knight RT. Socioeconomic disparities affect prefrontal function in children. J Cogn Neurosci. 2009; 21(6): 1106-1115.

[51] Gianaros PJ, Manuck SB. Neurobiological pathways linking socioeconomic position and health. Psychosom Med. 2010; 72(5): 450-61.

[52] Offord DR, Lipman EL. Lessening the impact of poverty on children. Paediatr Child Health. 1999; 4(8): 526-529.

[53] Jensen E. Enriching the brain. San Francisco, CA: Jossey Bass, A Wiley Imprint; 2006.

[54] Sapolsky RM. Stress and plasticity in the limbic system. Neurochem Res. 2003; 28(11): 1735-42.

[55] Hanson JL, Chandra A, Wolfe BL, Pollak SD. Association between income and the hippocampus. PLoS One. 2011; 6(5): e18712.

[56] Evans GE, Schamberg MA. Childhood poverty, chronic stress, and adult working memory. Proc Nat Acad Sci. 2009; 106(16): 6545-6549.

[57] Farah MJ, Shera DM, Savage JH, Betancourt L, Gianetta JM, Brodsky NL, Malmud EK, Hurt H. Childhood poverty: Specific associations with neurocognitive development. Brain Res. 2006; 1110(1): 166-74. 